\title{
Analysis of Symmetrical Fault in IEEE 14 Bus System for Enhancing Over Current Protection Scheme
}

\author{
Sheila Mahapatra and Mandeep Singh \\ Department of Electrical, Electronics and Communication Engineering, THE \\ NORTHCAP UNIVERSITY, Gurgaon, Haryana, India \\ mahapatrasheila@gmail.com,mandeepsingh@ncuindia.edu
}

\begin{abstract}
The paper provides a simulation model of IEEE 14 bus system for short circuit studies and analysis of symmetrical fault using MiPower software. At the event of a fault occurrence, short circuit studies are performed to obtain current flow magnitude at different time intervals for a power system until steady state condition is achieved. The paper gives simulation result for the current which flows in different parts of the power system immediately after occurrence of a fault. The data obtained is further used to decide switch gear ratings and circuit breakers and also aids in setting and coordination of protective relays. Further the simulation result provides data regarding the contribution of different power system apparatus to the fault located at different buses in the power system and it gives an efficient, accurate and easy way to analyze symmetrical faults in a given power system.
\end{abstract}

Keywords: Symmetrical Fault, Short Circuit and Load Flow Studies, Three Phase Fault

\section{Introduction}

Modern power systems are extensive, highly interconnected systems comprising of number of generators along with transmission and distribution networks. Fault analysis form an integral part of power system analysis and it consists of determining the bus voltages and line currents during the occurrence of various types of faults. The impact of the faults is generally considered very critical for power system operation as it leads to interruption of power supply and destabilizes the whole system. Real-time detection of faults as well as isolation of faulty section is necessary prior to occurrence of major stability issues which may drive the system to unstable operation. Thus faults detection is of immense significance from operational and economic point of view. Power transfer through transmission system is extended over large distances covering huge areas to cater to distribution networks located even at distant places. There may be occurrence of symmetrical short circuit faults or flash over of lines due to lightning, insulation damage, etc. Statistics show [2] that almost fifty percent of power system faults occur in the transmission and distribution networks. Though the symmetrical faults are rare, they generally lead to most severe current to flow against which the power system must be protected. However, majority of the faults involved in power system are unsymmetrical types where it is necessary to compute, voltages and currents in the system under such unbalanced operating conditions by use of symmetrical components. The grouping of fault is in terms of Unsymmetrical and Symmetrical type where a fault involving all the three phases on the power system is known as symmetrical fault or three-phase fault while the one involving one or two phases is known as unsymmetrical fault. Single Line-toground, Line-to-line and Double line-to-ground faults are unsymmetrical faults [4]. The current paper is structured as follows: In Section 2, IEEE 14 bus system which is the power system model under study is presented. The problem formulation and system data 
is given in section 3 . The simulation results and data are given in section 4 and conclusion in section 5 .

\section{Power System Model Under Study}

A single line diagram of the IEEE 14-bus standard system taken from [1] is shown in figure 2.1. It consists of five synchronous machines with IEEE type-1 exciters, three of which are

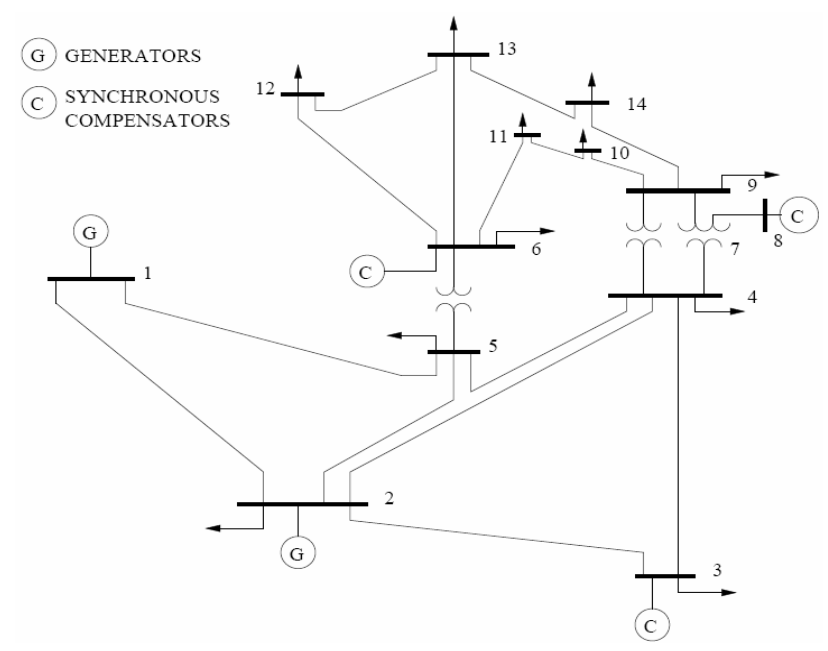

Figure 1. IEEE 14 Bus Standard System

Synchronous compensators used only for reactive power support. There are 11 loads in the system totaling 259 MW and 81.3 Mvar. The dynamic data for the generators exciters was selected from [1]. The system consists of 17 transmission lines and 11 loads.

\section{Problem Formulation and System Data}

\section{a. Analysis of Symmetrical Fault}

Electric systems occasionally experience short circuits which results in abnormally high currents. Over current protective devices should isolate faults at a given location safely, with minimal damage. The magnitudes of fault currents are usually estimated by calculations and the equipment is selected using the calculated results. In this paper, the symmetrical fault which is the most severe fault occurring in power system is simulated on the standard IEEE 14 bus system using MiPower software. The short-circuit analysis program analyzes the effect of 3-phase, line-to-ground, line-to-line, and line-to-line-toground faults on electrical distribution systems. The program calculates the total short circuit currents as well as the contributions of individual motors, generators, and utility ties in the system. Fault duties are in compliance with the latest editions of the ANSI/IEEE Standards (C37 series). When a symmetrical 3-phase fault occurs at the terminals of a synchronous generator, the resulting current flowing in the phases of the generator is represented as a transient DC component added on top of a symmetrical AC component. The total initial current is therefore typically 1.5 or 1.6 times the AC component alone. Three phase fault representation is given in figure 3.1 and its expression in terms of symmetrical component is also given in equations 3.1-3.3. 


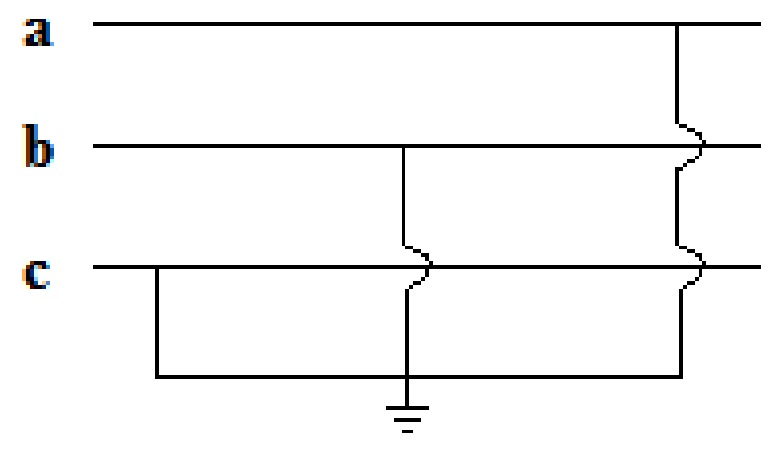

Figure 2. Representation of Three Phase to Ground Fault

\section{b. Problem Formulation}

The IEEE 14 bus system is simulated using MiPower software and load flow is conducted using N-R method to determine the pre fault voltage level at all the buses. After simulation, a symmetrical fault has been applied on bus 1 as given in the figure 4.1 to know the fault current withstanding capability of the circuit breaker located at bus 1 (Making and breaking Current value). Pre-fault voltage values, current values are the prerequisites for fault analysis.

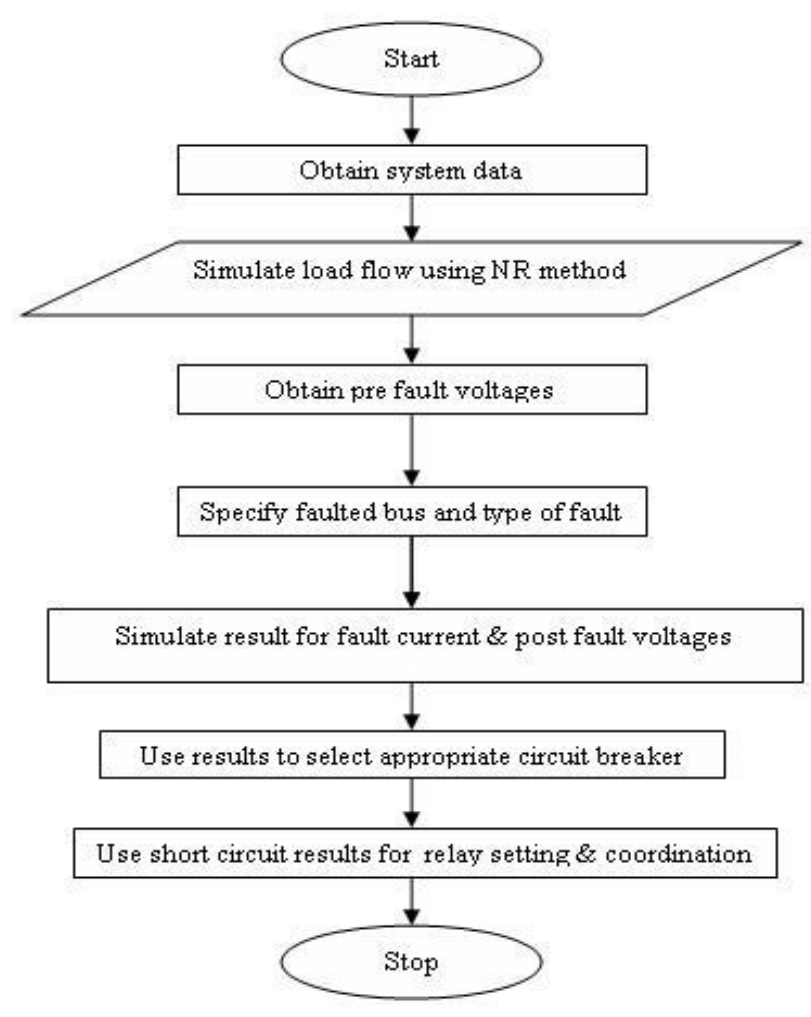

\section{Figure 3. Execution Steps for Fault Evaluation, Circuit Breaker Choices and Relay Setting}

Load flow analysis derived from pre-fault conditions provides voltage angle and magnitude data for individual bus, for designated load and generated real power and voltage state. The generator reactive power output and the reactive power flow for every bus can be logically calculated when the above data is available. The purpose of short 
circuit studies is to determine any or all of the following which includes: verification of protective device closing and latching capability, verification of protective device interrupting capability, protecting equipment from large mechanical forces (maximum fault $\mathrm{kA}$ ), $\mathrm{I}^{2} \mathrm{t}$ protection for equipment (thermal stress), selecting ratings or settings for relay coordination. The Execution steps for fault evaluation, circuit breaker choices and relay setting for over current protection at the event of occurrence of symmetrical fault is shown in figure 3.2.

\section{c. System Data}

The IEEE 14 bus system data for bus, transformers transmission lines and generators are given in the tables 3.1-3.4 respectively.

Table 1. Bus Data

\begin{tabular}{|l|l|l|l|l|l|l|}
\hline Bus & $\mathrm{V}(\mathrm{pu})$ & $\Delta(\operatorname{deg})$ & $\mathrm{P}_{\mathrm{G}}$ & $\mathrm{Q}_{\mathrm{G}}$ & $\mathrm{P}_{\mathrm{L}}$ & $\mathrm{Q}_{\mathrm{L}}$ \\
\hline 1 & 1.06 & 0 & 232.9 & -19.5 & 0 & 0 \\
\hline 2 & 1.045 & -5.015 & 40 & 36.92 & 21.7 & 12.7 \\
\hline 3 & 1.01 & -12.821 & 0 & 20.69 & 94.2 & 19 \\
\hline 4 & 1.0231 & -10.601 & 0 & 0 & 47.8 & -3.9 \\
\hline 5 & 1.0262 & -8.755 & 0 & 0 & 7.6 & 1.6 \\
\hline 6 & 1.0697 & -16.496 & 0 & 24 & 11.2 & 7.5 \\
\hline 7 & 1.0526 & -11.766 & 0 & 0 & 0 & 0 \\
\hline 8 & 1.0823 & -11.766 & 0 & 18.24 & 0 & 0 \\
\hline 9 & 1.0548 & -14.41 & 0 & 0 & 29.5 & 16.6 \\
\hline 10 & 1.0504 & -15.06 & 0 & 0 & 9 & 5.8 \\
\hline 11 & 1.0569 & -15.889 & 0 & 0 & 3.5 & 1.8 \\
\hline 12 & 1.0543 & -17.158 & 0 & 0 & 6.1 & 1.6 \\
\hline 13 & 1.0503 & -17.035 & 0 & 0 & 13.5 & 5.8 \\
\hline 14 & 1.0348 & -16.551 & 0 & 0 & 14.9 & 5 \\
\hline
\end{tabular}

Where, buses $1-5$ are at $220 \mathrm{kV}$ and 6-14 are at $132 \mathrm{kV} . \mathrm{P}_{\mathrm{G}}$ and $\mathrm{Q}_{\mathrm{G}}$ are real and reactive power generation and $\mathrm{P}_{\mathrm{L}}$ and $\mathrm{Q}_{\mathrm{L}}$ are real and reactive power of loads. Unit of active power is $\mathrm{MW} \&$ reactive power is in MVAr.

Table 2. Transformer Data

\begin{tabular}{|l|l|l|l|l|l|l|}
\hline \multirow{2}{*}{$\begin{array}{l}\text { From } \\
\text { Bus }\end{array}$} & To & \multicolumn{2}{|l|}{ Positive } & Zero & \\
\cline { 3 - 6 } & Bus & R p.u. & X p.u. & R p.u. & X p.u. & TAP \\
\hline 5 & 6 & 0.00006 & 0.556 & 0.00006 & 0.556 & 0.93 \\
\hline 4 & 7 & 0 & 0.048 & 0 & 0.048 & 0.98 \\
\hline 4 & 9 & 0 & 0.556 & 0.00006 & 0.556 & 0.97 \\
\hline
\end{tabular}

The breaker ratings from each bus is $15242 \mathrm{MVA}(220 \mathrm{kV})$ and breaker rating to each bus is $229 \mathrm{MVA}(132 \mathrm{kV})$

Table 3. Transmission Line Data

\begin{tabular}{|l|l|l|l|l|l|}
\hline From & To & $\mathrm{R}_{\mathrm{p}}$ (p.u) & $\mathrm{X}_{\mathrm{p}}$ (p.u) & FB-MVA & TB-MVA \\
\hline Bus1 & Bus2 & 0.01938 & 0.05917 & 15242 & 15242 \\
\hline Bus2 & Bus3 & 0.04699 & 0.19797 & 15242 & 15242 \\
\hline Bus2 & Bus4 & 0.05811 & 0.17632 & 15242 & 15242 \\
\hline Bus1 & Bus5 & 0.05403 & 0.2234 & 15242 & 15242 \\
\hline Bus2 & Bus5 & 0.05695 & 0.17388 & 15242 & 15242 \\
\hline Bus3 & Bus4 & 0.06701 & 0.17103 & 15242 & 15242 \\
\hline
\end{tabular}




\begin{tabular}{|l|l|l|l|l|l|}
\hline Bus4 & Bus5 & 0.01355 & 0.04211 & 15242 & 15242 \\
\hline Bus7 & Bus8 & 0 & 0.17615 & 229 & 229 \\
\hline Bus7 & Bus9 & 0 & 0.11001 & 229 & 229 \\
\hline Bus9 & Bus10 & 0.03181 & 0.0845 & 229 & 229 \\
\hline Bus6 & Bus11 & 0.0949 & 0.1989 & 229 & 229 \\
\hline Bus6 & Bus12 & 0.12291 & 0.25581 & 229 & 229 \\
\hline Bus6 & Bus13 & 0.06615 & 0.13027 & 229 & 229 \\
\hline Bus9 & Bus14 & 0.12711 & 0.27036 & 229 & 229 \\
\hline Bus10 & Bus11 & 0.08205 & 0.19207 & 229 & 229 \\
\hline Bus12 & Bus13 & 0.22092 & 0.1998 & 229 & 229 \\
\hline Bus13 & Bus14 & 0.17093 & 0.34802 & 229 & 229 \\
\hline
\end{tabular}

The Transmission line data gives the resistance and reactance values for the lines. FB MVA indicates the MVA rating from bus and TB MVA indicates the bus MVA values.

Table 4. Generator Data

\begin{tabular}{|l|l|l|l|l|l|l|}
\hline From & \multicolumn{3}{|l|}{ Positive } & \multicolumn{2}{l|}{ Negative } & \multicolumn{2}{l|}{ Zero } & \\
\hline Bus & R p.u & X p.u. & R p.u. & X p.u. & R p.u. & X p.u. \\
\hline 1 & 0.001 & 0.007 & 0.001 & 0.007 & 0.001 & 0.007 \\
\hline 2 & 0.002 & 0.011 & 0.002 & 0.011 & 0.002 & 0.01 \\
\hline 3 & 0.007 & 0.130 & 0.006 & 0.22 & 0.006 & 0.1 \\
\hline 6 & 0.002 & 0.162 & 0.002 & 0.22 & 0.002 & 0.1 \\
\hline 8 & 0.001 & 0.095 & 0.001 & 0.2 & 0.001 & 0.1 \\
\hline
\end{tabular}

Rating for circuit breakers (CB) in MVA connected to generators at buses 1-3 are 15242 and at bus 6-8 are 229 respectively.

\section{Simulation and Result}

\section{a. Proposed Approach}

The simulated result of symmetrical three phase fault applied on bus 1 for the IEEEE 14 bus system is shown in figure 4.1. The simulation result indicates the fault current in Amperes. Result provide in table 4.1 give the value of making and breaking current for the circuit breaker which are essential parameters to determine the correct rating of the device. Making is the initial peak current and the rated making capacity for a circuit breaker is determined by evaluating the max possible peak value of the short circuit current at the point of application. Breaking current is defined as the current required by the breaker to successfully open its contact at event of a fault to isolate the faulty section and these values are in the range of $\mathrm{kA}$ and the factor between the making and breaking current is 2.5. As per the industrial standards namely IEEE 37 series the fault level at $220 \mathrm{kV}$ is $40 \mathrm{kA}$. It is observed that the given circuit breaker rating is not adequate to limit the short circuit current to a safe value and thus the circuit breaker rating is required to be modified for the current system as shown in figure 4.1 to the next higher level of $63 \mathrm{kA}$. 


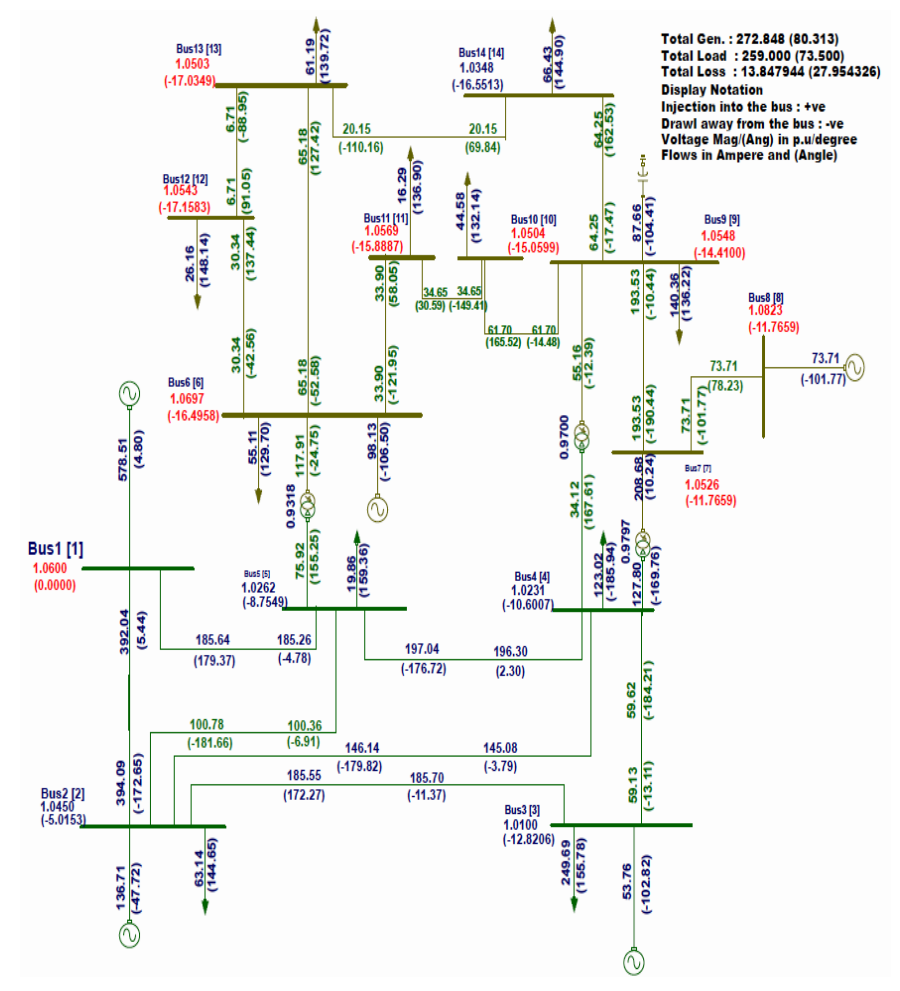

Figure 4. Simulation of Load Flow on IEEE 14 Bus System

It is also proposed to change the existing $220 \mathrm{kV}$ system to $400 \mathrm{kV}$ so that the circuit breaker ratings are adequate during the fault. The result for the Symmetrical three phase fault applied on bus 1 is given in the tables below:

\section{Table 5. Fault Current (Amp/deg) at Bus 1}

\begin{tabular}{|c|c|c|c|}
\hline \multicolumn{2}{|c|}{ Sequence $(1,2,0)$} & \multicolumn{2}{|c|}{ Phase $(a, b, c)$} \\
\hline Magnitude & Angle & Magnitude & Angle \\
\hline 40635 & -81.05 & 40635 & -81.05 \\
\hline 0 & -90 & 40635 & 158.95 \\
\hline 0 & -90 & 40635 & 38.95 \\
\hline \multicolumn{4}{|c|}{$\mathrm{r} / \mathrm{x}$ ratio of the short circuit path: 0.1575} \\
\hline \multicolumn{4}{|c|}{ peak asymmetrical short-circuit current*: $95368 \mathrm{amps}$} \\
\hline \multicolumn{4}{|c|}{$*$ pascc $=\mathrm{kx} \operatorname{sqrt}(2) \mathrm{x}$ if, $\mathrm{k}=1.6595$} \\
\hline
\end{tabular}

Table 4.1 indicates 3 phase momentary/peak current in amperes for half cycle and 1.5 to 4 cycle interrupting fault level for $220 \mathrm{kV}$ bus systems. The simulation result thus indicates the making/peak and braking current capacity for circuit breaker selection at the faulted bus 1

Table 6. Fault MVA Bus 1

\begin{tabular}{|l|l|}
\hline Sequence $(1,2,0)$ & Phase $(\mathrm{A}, \mathrm{B}, \mathrm{C})$ \\
\hline Magnitude & Magnitude \\
\hline 15484 & 15484 \\
\hline 0 & 15484 \\
\hline 0 & 15484 \\
\hline
\end{tabular}

The fault MVA for phase magnitude as observed from the result is same in all the three phases and for the sequence it will be reflected only in the positive sequence. 
Table 7. Post Fault Voltages in P.U.

\begin{tabular}{|c|c|c|c|c|c|}
\hline \multirow[t]{2}{*}{ Name } & \multicolumn{2}{|c|}{$\begin{array}{ll}\text { Sequence } & \text { Current } \\
(1,2,0) & \end{array}$} & \multicolumn{2}{|c|}{ Phase $(\mathrm{A}, \mathrm{B}, \mathrm{C})$} & \multirow{2}{*}{$\begin{array}{l}\text { Line-Line } \\
\text { Magnitude } \\
\text { p.u. on L-L base }\end{array}$} \\
\hline & $\mathrm{V}$ & Angle & $\mathrm{V}$ & Angle & \\
\hline \multirow[t]{3}{*}{ Bus1 } & 0 & -90 & 0 & -90 & 0 \\
\hline & 0 & -90 & 0 & 150 & 0 \\
\hline & 0 & -90 & 0 & 30 & 0 \\
\hline \multirow[t]{3}{*}{ Bus2 } & 0.833 & -1.43 & 0.833 & $\begin{array}{l}-1.43 \\
\end{array}$ & 0.833 \\
\hline & 0 & -90 & 0.833 & -121.4 & 0.833 \\
\hline & 0 & -90 & 0.833 & 118.57 & 0.833 \\
\hline \multirow[t]{3}{*}{ Bus3 } & 0.888 & -1.65 & 0.888 & -1.65 & 0.888 \\
\hline & 0 & -90 & 0.888 & -121.6 & 0.888 \\
\hline & 0 & -90 & 0.888 & 118.35 & 0.888 \\
\hline \multirow[t]{3}{*}{ Bus4 } & 0.774 & -1.5 & 0.774 & -1.5 & 0.774 \\
\hline & 0 & -90 & 0.774 & -121.5 & 0.774 \\
\hline & 0 & -90 & 0.774 & 118.5 & 0.774 \\
\hline \multirow[t]{3}{*}{ Bus5 } & 0.691 & -1.17 & 0.691 & -1.17 & 0.691 \\
\hline & 0 & -90 & 0.691 & -121.2 & 0.691 \\
\hline & 0 & -90 & 0.691 & 118.8 & 0.691 \\
\hline \multirow[t]{3}{*}{ Bus6 } & 0.902 & -0.82 & 0.902 & -0.82 & 0.902 \\
\hline & 0 & -90 & 0.902 & -120.8 & 0.902 \\
\hline & 0 & -90 & 0.902 & 119.18 & 0.902 \\
\hline \multirow[t]{3}{*}{ Bus7 } & 0.813 & -1.02 & 0.813 & -1.02 & 0.813 \\
\hline & 0 & -90 & 0.813 & -121.0 & 0.813 \\
\hline & 0 & -90 & 0.813 & 118.98 & 0.813 \\
\hline \multirow[t]{3}{*}{ Bus8 } & 0.934 & -0.28 & 0.934 & -0.28 & 0.934 \\
\hline & 0 & -90 & 0.934 & -120.3 & 0.934 \\
\hline & 0 & -90 & 0.934 & 119.72 & 0.934 \\
\hline \multirow[t]{3}{*}{ Bus9 } & 0.827 & -0.53 & 0.827 & -0.53 & 0.827 \\
\hline & 0 & -90 & 0.827 & -120.5 & 0.827 \\
\hline & 0 & -90 & 0.827 & 119.47 & 0.827 \\
\hline \multirow[t]{3}{*}{ Bus10 } & 0.84 & -0.54 & 0.84 & -0.54 & 0.84 \\
\hline & 0 & -90 & 0.84 & -120.6 & 0.84 \\
\hline & 0 & -90 & 0.84 & 119.46 & 0.84 \\
\hline \multirow[t]{3}{*}{ Bus11 } & 0.87 & -0.64 & 0.87 & -0.64 & 0.87 \\
\hline & 0 & -90 & 0.87 & -120.7 & 0.87 \\
\hline & 0 & \begin{tabular}{|l|}
-90 \\
\end{tabular} & 0.87 & 119.36 & 0.87 \\
\hline \multirow[t]{3}{*}{ Bus12 } & 0.897 & -0.85 & 0.897 & -0.85 & 0.897 \\
\hline & 0 & -90 & 0.897 & -120.9 & 0.897 \\
\hline & 0 & -90 & 0.897 & 119.15 & 0.897 \\
\hline \multirow[t]{3}{*}{ Bus13 } & 0.891 & -0.75 & 0.891 & -0.75 & 0.891 \\
\hline & 0 & -90 & 0.891 & -120.8 & 0.891 \\
\hline & 0 & \begin{tabular}{|l|}
-90 \\
\end{tabular} & 0.891 & 119.25 & 0.891 \\
\hline \multirow[t]{3}{*}{ Bus14 } & 0.855 & -0.61 & 0.855 & -0.61 & 0.855 \\
\hline & 0 & \begin{tabular}{|l|}
-90 \\
\end{tabular} & 0.855 & -120.6 & 0.855 \\
\hline & 0 & \begin{tabular}{|l|}
-90 \\
\end{tabular} & 0.855 & 119.39 & 0.855 \\
\hline
\end{tabular}

As observed from the result of post fault voltages during the fault, voltage at bus 1 is zero and voltage drop is reflected in the neighboring buses. 
Table 8. Fault Contribution From Shunt Connection

\begin{tabular}{|l|l|l|l|l|l|}
\hline From & \multicolumn{4}{|l|}{ Current (Amps/Degree) } & MVA \\
\hline \multirow{4}{*}{ Name } & \multicolumn{2}{l}{$\begin{array}{l}\text { Sequence } \\
(1,2,0)\end{array}$} & \multicolumn{2}{l|}{ Phase (A,B,C) } & Phase (A,B,C) \\
\hline & I & Angle & I & Angle & Magnitude \\
\hline Bus1 & 36371 & 98.13 & 36371 & 98.13 & 13859 \\
\hline \multirow{5}{*}{ Bus2 } & 0 & -90 & 36371 & -21.87 & 13859 \\
\cline { 2 - 6 } & 0 & -90 & 36371 & -141.9 & 13859 \\
\hline \multirow{5}{*}{} & 0 & 106.82 & 3731 & 106.8 & 1422 \\
\cline { 2 - 6 } & 0 & -90 & 3731 & -13.18 & 1422 \\
\cline { 2 - 6 } & & -90 & 3731 & -133.2 & 1422 \\
\hline
\end{tabular}

The elements that contribute current to a short circuit are generators, synchronous condensers, delta - star grounded transformers. Details of fault current contribution are given in table 4.4 and shown in figure 4.1.

Table 9. Three Phase Fault Level

\begin{tabular}{|l|l|l|l|}
\hline Name & Bus kV & 3PH-fMVA & Fault I \\
\hline & NOMINAL & & kA \\
\hline Bus1 & 220 & 15483.6 & 40.635 \\
\hline Bus2 & 220 & 0.3 & 0.001 \\
\hline Bus3 & 220 & 0.3 & 0.001 \\
\hline Bus4 & 220 & 0.3 & 0.001 \\
\hline Bus5 & 220 & 0.3 & 0.001 \\
\hline Bus6 & 132 & 0.2 & 0.001 \\
\hline Bus7 & 132 & 0.2 & 0.001 \\
\hline Bus8 & 132 & 0.2 & 0.001 \\
\hline Bus9 & 132 & 0.2 & 0.001 \\
\hline Bus10 & 132 & 0.2 & 0.001 \\
\hline Bus11 & 132 & 0.2 & 0.001 \\
\hline Bus12 & 132 & 0.2 & 0.001 \\
\hline Bus13 & 132 & 0.2 & 0.001 \\
\hline Bus14 & 132 & 0.2 & 0.001 \\
\hline
\end{tabular}

Table 4.5 gives simulation result after application of three phase fault, the fault current level at bus 1 is $40.635 \mathrm{kA}$.This analysis helps to design and provide setting for circuit breakers and relay coordination leading to proper power system protection. Figure 4.2 gives the detailed result of short circuit level at the faulted bus 1 and various elements contributing towards the fault. Since the type of fault is symmetrical and circuit breaker rating fixed to require interrupting capacity, the relays placed at the faulted bus are both over current type as shown in figure 4.2. Settings for the current transformer (CT) and over current relays R1and R2 based on the simulation results obtained are given in table 4.6 The primary current settings of the CT are obtained by calculating the current under normal load flow conditions. The secondary setting are decided based upon the type of protection scheme that is implemented, the element type as well as the nature of fault. The plug setting indicates the pick up current of the relay required for sensing the fault and initiate the tripping of the circuit breaker for clearing the fault. Simulation result of the relay coordination intimates the time dial settings (TDS) and simultaneously gives the calculation of the operating time for closing fault current taking into account the pick up 
setting as in table 4.7. On the occurrence of fault on bus $1 \mathrm{R} 2$ provides the primary protection and if it fails then R1will operate as a back up protection based upon the discrimination time. Discrimination time is the difference between time of operation (TOP) of R1 and R2. As per calculation done by the software it is $0.3228 \mathrm{sec}$ and is within prescribed limits. Figure 4.4 depicts the waveform for over current protection scheme using relays $\mathrm{R} 1$ and $\mathrm{R} 2$.

Table 10. Relay Setting

\begin{tabular}{|l|l|l|l|l|l|}
\hline Relay & $\begin{array}{l}\text { CT -P } \\
(\mathrm{A})\end{array}$ & $\begin{array}{l}\text { CT-S } \\
(\mathrm{A})\end{array}$ & $\begin{array}{l}\text { Plug } \\
\text { Setting } \\
(\%)\end{array}$ & $\begin{array}{l}\text { Plug } \\
\text { setting } \\
(\text { prim }) \\
(\mathrm{A})\end{array}$ & $\begin{array}{l}\text { Plug } \\
\text { setting } \\
\text { sec }) \\
(\mathrm{A})\end{array}$ \\
\hline R1 & 600 & 5 & 130 & 780 & 6.5 \\
\hline R2 & 400 & 5 & 130 & 520 & 6.5 \\
\hline
\end{tabular}

Graphical representation obtained from simulation of three phase fault on bus 1 of the model under study is given in figure 4.3.

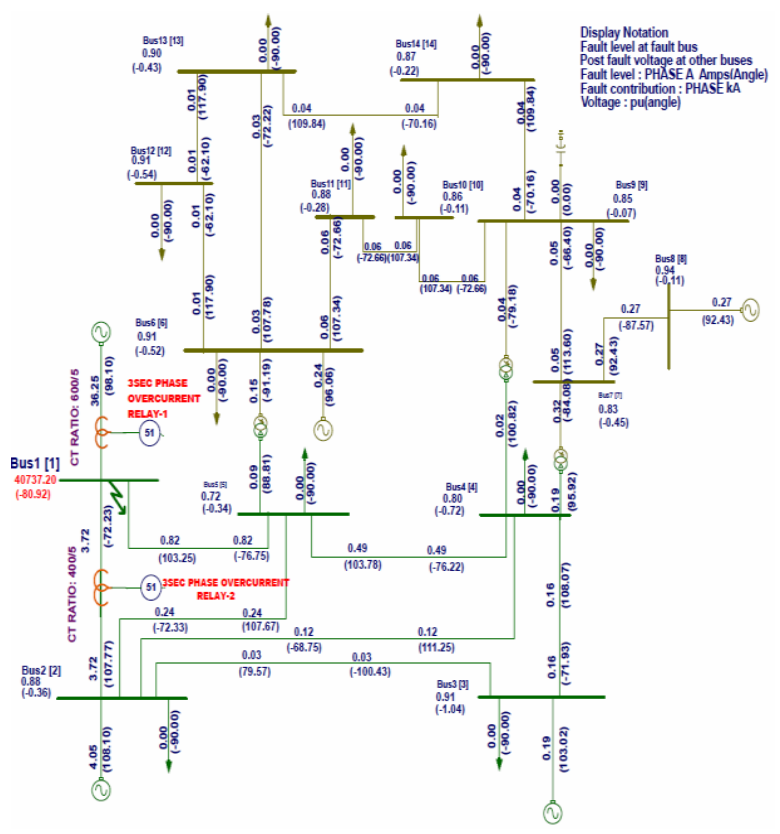

Figure 5. Simulation of Three Phase Symmetrical Fault and Over Current Relay Coordination on IEEE 14 Bus System

Table 11. Relay Coordination

\begin{tabular}{|l|l|l|l|l|l|}
\hline Relay & TDS & $\begin{array}{l}\text { Close in } \\
\text { fault } \\
\text { current } \\
\text { (amps) }\end{array}$ & $\begin{array}{l}\text { TOP } \\
\text { for closing } \\
\text { in fault } \\
(\mathrm{sec})\end{array}$ & $\begin{array}{l}\text { Remote } \\
\text { bus fault } \\
\text { current } \\
\text { (amps) }\end{array}$ & $\begin{array}{l}\text { Time for } \\
\text { remote } \\
\text { fault } \\
(\mathrm{sec})\end{array}$ \\
\hline R1 & 0.19 & 36246.46 & 0.4381 & 36246.46 & 0.4381 \\
\hline R2 & 0.05 & 37043.48 & 0.1153 & Will not act as back up \\
\hline
\end{tabular}




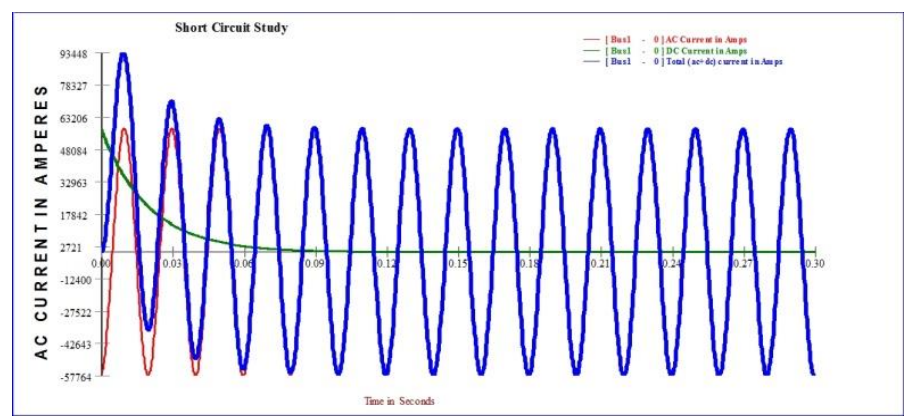

Figure 6. Waveform for Three Phase Symmetrical Fault with Dc Component

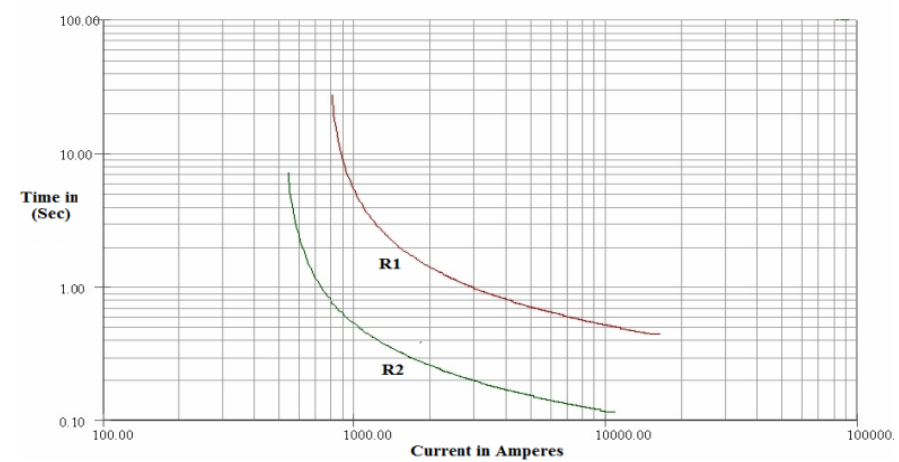

Figure 7. Phase Relay Coordination Curve of Fault at Bus 1(220kv)

\section{Conclusion}

This paper presents simulation of IEEE 14 bus system using MiPower software for symmetrical three phase fault analysis. The result obtained by applying a three phase fault on bus 1 is used for circuit breaker selection and over current relay setting which helps in enhancing system operation, protection and reliability. In comparison with simulation studies done earlier with other software tools, the result of this paper is better as it provides detailed information for fault current, fault MVA, post fault voltages at all the buses, values of making and breaking current, contribution of various elements towards the fault. Further, it gives complete system behavior during occurrence of three phase fault which is considered as rarest but severest of all the faults occurring in a given power system.

\section{Appendix}

System Data: All data are in p.u. unless specified otherwise

Base MVA: 100

Transformers Rating:

$\mathrm{T}_{1:} 132 / 220 \mathrm{kV}, 150 \mathrm{MVA}, \Delta$-y grounded $\% \mathrm{Z}=0.556$ p.u. tap $1-45$, set tap 13 , NT 23

$\mathrm{T}_{2}: 132 / 220 \mathrm{kV}, 150 \mathrm{MVA}, \Delta-\mathrm{y}$ grounded $\% \mathrm{Z}=0.556$ p.u. tap $1-21$, set tap 9 , NT 11

$\mathrm{T}_{3}: 132 / 220 \mathrm{kV}, 150 \mathrm{MVA}, \Delta-\mathrm{y}$ grounded $\% \mathrm{Z}=0.556$ p.u. tap 1-38, set tap 17, NT 20.

\section{References}

[1] S. Kamel, M. Kodsi and C. A. Canizares, "Modeling and simulation of IEEE 14 bus system with facts controllers", Technical Report, (2003), p. 3.

[2] B. Ram and D. N. Vishwakarma, "Power system protection and switchgear", NewDelhi: Tata McGrawHill, (1995).

[3] P. M. Anderson and A. A. Fouad, "Power System Control and Stability", IEEE Press, (1994). 
[4] M. Tijani and D. Olatunji, "An Evaluation of Three-Phase Fault Currents on the Nigerian 330kV Transmission Gride, Journal of Research in Technology and Engineering Management, vol. 4, no. 2, (2011), pp. 37-45.

[5] S. Saha, M. Aldeen, C. P. Tan, "Unsymmetrical fault diagnosis in transmission /distribution networks", Electrical Power and Energy Systems, vol. 45, (2013), pp. 252-263.

[6] A. G. Adepoju, O. A. Komolafe, M. A. Tijani and A. O. Bisiriyu, "Fault analysis for circuit breakers ratings determination on nigerian $330 \mathrm{kv}$ transmission grid", The International Journal Of Engineering And Science, vol. 2, (2013), pp. 116-123.

[7] A. Muhammad, "Simulation of Different Types of Faults on Northern Iraq Power System", IGEC, VIvol. 28, (2011).

[8] A. Ibe and N. Uzonwa, "Power System Simulation for Short Circuit Current in the Selection of Switchgears", Nigerian Journal of Industrial and Systems Studies, vol. 4, no. 3, (2005), pp. 9-15.

[9] M. Tijani and D. Olatunji, "An Evaluation of Three-Phase Fault Currents on the Nigerian 330kV Transmission Grid", Journal of Research in Technology and Engineering Management, vol. 4, no. 2, (2011), pp. 37-45.

[10] Okelola, "Fault Analysis: An Application of Venin's Method to 330kV Transmission Grid System in Nigeria", LAUTECH Journal of Engineering and Technology, vol. 3, no. 1, (2005), pp. 30-43.

[11] O. Okemiri, "Basic Protection Scheme on Power System", The Nigerian Tribune, (2008), pp. 24.

[12] I. J. Nagrath and D. P. Kothari, "Power System Engineering", Tata McGraw-Hill Publishing Company Limited, (2010), New Delhi.

[13] C. L. Wadhwa, "Electrical Power System", John Wiley and Sons, (1991), New Delhi, India.

[14] Standard Application Guide for AC High-Voltage Circuit Breakers Rated on a Symmetrical Current Basis and Supplements, IEEE C37.010, (1999).

[15] F. Crusca and M. Aldeen, "Design of fault detection filters for multi-machine power systems", In Presented at the 5th Asian control conference, (2004).

[16] C. P. Tan, "Fault diagnosis in transmission networks of linear and nonlinear power systems". In: presented at the European control conference, (2009). 
International Journal of Future Generation Communication and Networking Online Vol. 9, No. 4, (2016) 